\title{
Analytical study on indications of primary cesarean section in tertiary care hospital
}

\author{
Arpitha S. Ballu, Asha M. B.*
}

Department of Obstetrics and Gynecology, Mysore Medical College and Research Institute, Mysore, Karnataka, India

Received: 08 July 2019

Accepted: 12 July 2019

\section{*Correspondence:}

Dr. Asha M. B.,

E-mail: drashamb@gmail.com

Copyright: (C) the author(s), publisher and licensee Medip Academy. This is an open-access article distributed under the terms of the Creative Commons Attribution Non-Commercial License, which permits unrestricted non-commercial use, distribution, and reproduction in any medium, provided the original work is properly cited.

\begin{abstract}
Background: Cesarean delivery is a commonest obstetric surgical procedure performed. WHO stated that regional cesarean section rate should not exceed 10 to $15 \%$. However in many countries cesarean delivery has increased steadily over years. Hence present study is conducted to analyze various indications of primary cesarean section in a tertiary hospital, with an aim to reduce cesarean section rate.

Methods: This is a retrospective study conducted in Cheluvamba hospital, Mysore Medical College Research Institute, Mysore, which is a tertiary care centre. For a period of 6months from $1^{\text {st }}$ June 2018 to $31^{\text {st }}$ November 2018 Inclusion criteria: All primary cesarean section done at Cheluvamba hospital during study period were included. Exclusion criteria: Previous cesarean section, patients with previous history of laparotomy done for any obstetric or gynecological cause were excluded.

Results: During the study period there was 3799 number of cesarean section. Amongst these 983 cases were primary cesarean section done for varying indications. Hence the rate of cesarean section in our hospital is $25.87 \%$. There were $40.3 \%$ cases of fetal distress, failed induction (13.6\%), breech $(10 \%)$, CPD (8\%), IUGR with poor BPP (1.8\%) Ante partum haemorrhage (3\%), DTA $(3.5 \%)$.

Conclusions: From our study, we would conclude that rising trend in cesarean section is an alarming issue. Measures need to be taken to reduce cesarean delivery like Regular use of partograph, Judicious use of amniotomy, oxytocin with inducing agents, Expertization of skills to conduct instrumental vaginal delivery, which is a lost art in modern obstetrics.
\end{abstract}

Keywords: Cesarean section, Fetal, Maternal, Primary

\section{INTRODUCTION}

Cesarean delivery is a surgical procedure that delivers a viable fetus (along with placenta and membranes) through an incision that passes through both the mothers abdomen (laparotomy) and the uterus (hysterotomy). If the fetus is previable, the same procedure is termed as abdominal hysterotomy. By definition, cesarean delivery excludes operations performed to deliver either an extrauterine pregnancy or a fetus extruded from the uterus after rupture ${ }^{1,2}$
Cesarean Section is described as primary (first cesarean) and repeat cesarean delivery (any cesarean after first). ${ }^{1}$

Cesarean delivery has a long and complex history. In past cesarean was rarely performed in living women. It was used as a last resort to save mothers life or salvage a child (peri-postmortem emergencies were performed).It was performed when all other methods of delivery had failed. With the evolution of safe surgical practice by late nineteenth century, cesarean delivery progressively evolved from a dreadful, dangerous and desperate 
procedure to its status today (alternative to vaginal delivery) ${ }^{2}$

In 1985 WHO stated that regional cesarean section rate should not exceed 10 to $15 \%$.However in many countries cesarean delivery has increased steadily over years. ${ }^{3}$ As per the lancet report in 2018, in India percentage of cesarean deliveries have doubled, going up from 9 to $18.5 \%$ (this increase corresponds with global increment $21 \%) .{ }^{3,4}$ The cesarean rate varies from state to state across our country. Highest number reported in Chandigarh $(98 \%)$, followed by Delhi $(67.83 \%) .^{5}$ The rising rate of cesarean delivery is an alarming concern worldwide.

There are various types of cesarean section which has evolved over years. Most commonly practiced type is lower segment cesarean section. ${ }^{6}$

There are various indications for cesarean section. Classification of cesarean section based on the timings when a cesarean section needs to be done is. ${ }^{6}$

Category 1 or emergency cesarean section- ideally cesarean section should be done within the next 30 minutes, as there is an immediate threat to mother or to the fetus. Ex: cord prolapse, scar rupture.

Category 2 or urgent cesarean section -cesarean delivery should be completed within $60-75$ minutes as there is maternal or fetal compromise. Ex: Abnormal fetal heart rate.

Category 3 or scheduled cesarean section - There are various indications in this category. These are neither emergency nor elective. Ex: Preterm IUGR.

Category 4 or elective cesarean section - Here mother and staff select the date and time of delivery. Ex: Previous cesarean section where mother request a repeat Cesarean section. In this category it is preferred to do Cesarean delivery after 39 weeks to reduce the incidence of tachypnea of the newborn and its admission to NICU.

The other classification of indication of cesarean delivery is. $^{7,8}$

- Maternal conditions like-ex: prior cesarean delivery

- Maternal and fetal condtion like ex: Cephalopelvic disproportion

- Fetal condition-ex: Macrosomia

According to a 7 year analysis study at Yela University USA, rate of primary cesarean section has increased by $50 \%$. The varying indications for primary cesarean sections are Nonreassuring FHR (32\%), labor arrest disorders (18\%), Multiple gestations (16\%), Suspected macrosomia (10\%), preeclampsia (10\%), Maternal request $(8 \%)$, maternal fetal condition $(5 \%)$ and other obstetric condition (1\%). ${ }^{9}$ Rising primary cesarean delivery which attributes to increase in previous cesarean delivery rate. Hence present study is taken up to analyze various indications in primary cesarean in a tertiary hospital, with an aim to reduce cesarean section rate.

\section{METHODS}

This is a retrospective study conducted in Cheluvamba hospital, Mysore Medical College Research Institute, which is a tertiary care centre. For a period of 6months from $1^{\text {st }}$ June 2018 to $31^{\text {st }}$ November 2018. Data were collected from hospital medical records section on a proforma and statistical analysis was done using statistical package for social science (SPSS) window software.

\section{Inclusion criteria}

- All primary cesarean section done at cheluvamba hospital during study period was included.

\section{Exclusion criteria}

- Previous cesarean section, patients with previous history of laparotomy done for any obstetric or gynecological cause were excluded.

\section{RESULTS}

During the study period there were 3799 number of cesarean section. Amongst these 983 cases were primary cesarean section done for varying indications. Hence the rate of cesarean section in our hospital is $25.87 \%$. $45.5 \%$ of cases were aged between 21 to 25 years as shown in table 1 .

Table 1: Age wise distribution of primary cesarean section $(\mathrm{N}=983)$.

\begin{tabular}{|lll|}
\hline Age in years & Number & Percent $(\%)$ \\
\hline$\leq 20$ & 253 & 25.7 \\
\hline $21-25$ & 447 & 45.5 \\
\hline $26-30$ & 201 & 20.4 \\
\hline $31-35$ & 66 & 6.7 \\
\hline$\geq 35$ & 16 & 1.6 \\
\hline
\end{tabular}

Being a tertiary care centre, many cases were referred from surrounding rural population. Hence $77 \%$ of them were hailing from rural area as shown in Figure 1. 70.2\% of cases of primary cesarean section were primigravida as shown in Table $2.90 .6 \%$ cases were term pregnancies while $9.4 \%$ were preterm. In our study 775 cases were emergency cesarean section while 208 cases were elective. There were various indications for primary cesarean section, amongst them $40.3 \%$ of cases were performed due to fetal distress, followed by failed induction (10.1\%), breech (10.1\%), CPD (8\%), DTA $(3.6 \%)$, cord prolapse $(0.7 \%)$ as shown in Table 3 . 


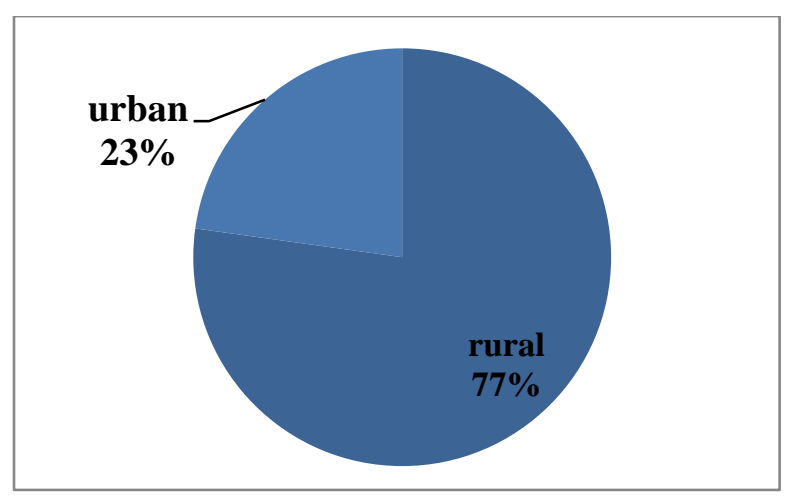

Figure 1: Distribution based on locality.

Table 2: distribution based on parity.

\begin{tabular}{|lll|}
\hline Parity & Number & Percent (\%) \\
\hline Primigravida & 690 & 70.2 \\
\hline Gravida -2 & 199 & 20.2 \\
\hline Gravida -3 & 70 & 7.1 \\
\hline Gravida-4 & 24 & 2.4 \\
\hline
\end{tabular}

Table 3: Indication for primary cesarean section.

\begin{tabular}{|l|l|l|}
\hline Indications for LSCS & Number & Percentage \\
\hline CPD & 79 & 8.0 \\
\hline Breech & 99 & 10.1 \\
\hline Fetal distress & 396 & 40.3 \\
\hline Failed induction & 134 & 13.6 \\
\hline Failure to progress & 47 & 4.8 \\
\hline IUGR & 8 & 0.8 \\
\hline Poor BPP & 10 & 1.0 \\
\hline PIH & 26 & 2.6 \\
\hline Multifetal Gestation & 18 & 1.8 \\
\hline Transverse lie & 10 & 1.0 \\
\hline Placenta previa & 22 & 2.2 \\
\hline Abruptio placenta & 8 & 0.8 \\
\hline DTA & 35 & 3.6 \\
\hline Precious pregnancy & 42 & 4.3 \\
\hline Brow presentation & 10 & 1.0 \\
\hline $\begin{array}{l}\text { Secondary arrest of } \\
\text { descent \&dilatation }\end{array}$ & 13 & 1.3 \\
\hline Cord prolapsed & 7 & 0.7 \\
\hline Oligohydramnios & 19 & 1.9 \\
\hline
\end{tabular}

There were $84 \%$ of women were not willing for any contraceptive methods while $14.1 \%$ opted for intracesarean PPIUCD and only $1.8 \%$ underwent concurrent tubectomy as shown in Table 4.

Table 4: Contraceptive method opted during primary cesarean section.

\begin{tabular}{|lll|}
\hline Contraception & Number & Percent \\
\hline Tubectomy & 18 & 1.8 \\
\hline Intracesarean PPIUCD & 139 & 14.1 \\
\hline None & 826 & 84.1 \\
\hline
\end{tabular}

\section{DISCUSSION}

We have analyzed 983 cases of primary cesarean section. Being a tertiary care hospital majority of the cases were referred, hence we have a higher rate of primary cesarean section 25.87\%, similar incidence was noted in Prameela et al, study. ${ }^{10}$ Amongst them $65.9 \%$ of them were aged between 21 to 30 years, while Samal R et al, study reports $83.8 \%$ in same age group. ${ }^{11}$

National family health survey found that cesarean section rate is higher in urban private hospital $(45 \%)$ than rural private hospital $(38 \%){ }^{5}$ Our hospital receives majority patient load from surrounding rural area, hence in contrast with this present study has $77 \%$ of rural population undergoing primary cesarean section.

Rate of primary cesarean in primigravida v/s multigravida in our study is $70.2 \mathrm{v} / \mathrm{s} 30.8 \%$ while in Sharma $\mathrm{R}$ et al, study it is $57.1 \mathrm{v} / \mathrm{s} 42.7 \% .^{12}$

In our study $78.8 \%$ of emergency cesarean section was performed while $21.2 \%$ cases were taken electively. Similar incidence was reported in Onankpa et $\mathrm{al}^{13}$ study (80.6 and $19.4 \%)$.

To analyze the indication of primary section which is our main objective of study, there were $40.3 \%$ cases of fetal distress, failed induction (13.6\%), breech (10\%), CPD (8\%), IUGR with poor BPP (1.8\%) Antepartum haemorrhage (3\%) DTA (3.5\%), while Sharma et al study shows CPD (15.8\%), breech (12.5\%), MSL (11.2\%), failed induction $(9 \%)$, while Samal $\mathrm{R}$ et al, study shows fetal distress (42.6\%) malpresentation (26.4\%) CPD $(14.7 \%)$ and cord prolapse $(1.5 \%) .{ }^{11,12}$

The rate of cesarean section has increased tremendously. There are few indications where performing cesarean section is very much essential to prevent maternal and fetal morbidity and mortality like transverse lie in labour, placenta previa, DTA, brow presentation, cord prolapse, severe IUGR with poor BPP, severe PE with unfavourable cervix, severe oligohydramnios with fetal compromise.

However there are few indications where trial of labour should be given before deciding for cesarean section like CPD, Breech, Multifetal gestation.

Cephalopelvic disproportion is a diagnosis of exclusion. Unfortunately, there is no way to accurately predict it. It has been estimated that thousands of unnecessary cesarean deliveries are performed in low risk pregnancies to prevent one true CPD. ${ }^{14}$

Arrest of labour can be evaluated by plotting partograph. Amniotomy and oxytocin can be initiated if uterine activity is inadequate. Majority of gravid respond to this intervention and achieve vaginal delivery. ${ }^{15}$ 
Rate of failed induction can be reduced by inducing when cervix is favorable, prior sweeping of membranes followed by induction helps in response to inducing agent and shortens the induction to delivery interval. ${ }^{16}$

Breech in second stage of labor is usually left for assisted breech delivery in multigravida in our institute however studies show high perinatal morbidity and mortality in assisted breech delivery. Hence individualization of decisions should be made in the management of cases.

Fetal distress in first stage of labour is an indication for cesarean delivery. However, FHR variability and prolonged second stage of labour instrumental delivery can be considered if the criteria for instrumental vaginal delivery is fulfilled. ${ }^{17}$

\section{CONCLUSION}

From our study, we would conclude that rising trend in cesarean section is an alarming issue. Measures need to be taken to reduce cesarean delivery like Regular use of partograph, Judicious use of amniotomy, oxytocin with inducing agents, Expertization of skills to conduct instrumental vaginal delivery, which is a lost art in modern obstetrics. However in the present medico legal era every case management has to be individualized depending on the clinical situation and available resources.

\section{ACKNOWLEDGMENTS}

Author thanks Dr. Prashanth, Assistant professor. Dept of Community Medicine MMC and RI Mysore for helping in analysis of data.

Funding: No funding sources Conflict of interest: None declared

Ethical approval: The study was approved by the Institutional Ethics Committee

\section{REFERENCES}

1. Malhotra N, Puri R, Malhotra J, Kurjak A, Chervenak FA. Donald School Manual of Practical Problems in Obstetrics. $1^{\text {st }}$ ed. JP Medical Ltd; 2012.

2. John Patrick o'Grady, Timothy K. Fitzpatrick, Martin L. Gimovsky, Locy. Bager-Zwirello. Kevin Giordano, Operative obstetrics. Cesarean delivery and Surgical Sterilization, Chapter 18, $2^{\text {nd }}$ Ed. 509.

3. WHO-Appropriate technology for birth. Lancet 1985; 2:436-7.

4. Ye J, Betrán AP, Guerrero Vela M, Souza JP, Zhang J. Searching for the optimal rate of medically necessary cesarean delivery. Birth. 2014;41(3):23744.

5. National family health survey (NFHS-4) 2012-14. Mumbai: International institute for population sciences (IIPS) and Macro International; 2009. Available at: http://www.rchiips.org/nfhs/nfhs 4.shtml (cital 2014 december 2018).

6. Thomas J, Paranjothy S. RCOG Clinical Effectiveness Support Unit. The National Sentinel Caesarean Section Audit Report. RCOG Press; 2001:49-53.

7. William obstetrics, "Cesarean Delivery." 24th edition;588, F.Gary Cunningham, Kenneth J Leveno, Steven L.Bloom, Catherine.Y.Spong, Jodi.S.Dasha.

8. Cesarean section, 7th edition;571, Renu Mishra, Nupur Guptha, Ian Donald.

9. Barber EL, Lundsberg LS, Belanger K, Pettker CM, Funai EF, Illuzzi JL. Indications contributing to the increasing cesarean delivery rate. Obstet Gynecol. 2011;118(1):29-38.

10. Dr. R C Prameela, Dr. Asma Farah, Dr. Bhanumati, S. Prajwal, "Analysis of cesarean section rate in a tertiary hospital, according to Robson's 10 group classification system (TGCS)". IOSR-JDMS. 2015;14(2):46-49.

11. Samal R, Palai P, Ghose S. Clinical study of primary caesarean section in multiparous women in a tertiary care hospital. International J Reprod, Contracept, Obstet Gynecol.;5(5):1507. www.ijrcog.orgl

12. Reena Sharma, poojan dogra. International $\mathbf{J}$ Reproduct, Contracept, Obstet Gynecol. 2017;6(10):4367-4371 www.ijrcog.org

13. Onankpa B, Ekele B. Fetal outcome following cesarean section in university teaching hospital. J Natl Med Assoc. 2009;101:578-81.

14. Rouse DJ, Owen J, Goldenberg RL, Cliver SP. The effectiveness and costs of elective cesarean delivery for fetal macrosomia diagnosed by ultrasound. JAMA. 1996;276(18):1480-6.

15. Friedman E. An objective approach to the diagnosis and management of abnormal labor. Bull N Y Acad Med 48:842.

16. Heinemann J, Gillen G, Sanchez-Ramos L, Kaunitz AM. Do mechanical methods of cervical ripening increase infectious morbidity? A systematic review. Am J Obstet Gynecol. 2008;199(2):177-88.

17. Gabbe SG, Landen MB, Nichyl JR, Galon HL, Simpson JL. Obstetrics normal and problem pregnancies. Operative Vaginal Delivery, Chapter 15, $6^{\text {th }}$ Ed: 302.

Cite this article as: Arpitha SB, Asha MB.

Analytical study on indications of primary cesarean section in tertiary care hospital. Int J Reprod Contracept Obstet Gynecol 2019;8:3179-82. 